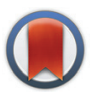

CrossMark \&lick for updates

Cite this: Inorg. Chem. Front., 2015, 2, 290

Received 25th November 2014, Accepted 23rd January 2015

DOI: 10.1039/c4qi00211c

rsc.li/frontiers-inorganic

\section{Size dependent effect of new organometallic triptycene tectons on the dimensions of self-assembled macrocycles $\uparrow$}

\author{
Sourav Chakraborty, ${ }^{a}$ Sourav Bhowmick, ${ }^{a}$ Jianqiu Ma, ${ }^{\mathrm{b}}$ Hongwei $\operatorname{Tan}^{\mathrm{b}}$ and \\ Neeladri Das*a
}

\begin{abstract}
The design, synthesis and characterization of two new triptycene-containing ditopic Pt(॥) organometallic complexes is being reported. These complexes comprise of two peripheral bis(trans-trialkylphosphine)platinum units either directly $\sigma$-bonded to the central triptycene moiety or connected via a bridging ethynyl spacer linkage. The potential utility of these organometallic complexes as ditopic acceptor building blocks for the construction of neutral metallasupramolecular macrocycles containing the triptycene motif is explored. Triptycene motif containing supramolecules were characterized using multinuclear NMR (including ${ }^{1} \mathrm{H}$ DOSY), mass spectrometry (MALDI-TOF-MS) and elemental analyses. While the selfassembly of a longer acceptor linker with a terephthalate group results in the formation of a [3 + 3] selfassembled macrocycle, the use of a relatively shorter acceptor linker yields the corresponding [2 + 2] supramolecular framework. The shapes and dimensions of these supramolecular structures were also predicted by geometry optimization using PM6 semiempirical molecular orbital methods and the results corroborate well with the experimental observations. These two self-assembled macrocycles are unique examples of triptycene-based neutral "platinamacrocycles" reported in the literature to date. An investigation as to how the shape and size of the resulting discrete supramolecular framework is affected upon changing the length and rigidity of the triptycene-based acceptor linkers is discussed.
\end{abstract}

\section{Introduction}

Design and self-assembly of finite nanoscopic supramolecular coordination complexes (SCCs) via a coordination driven selfassembly approach is an important area of research in supramolecular chemistry. ${ }^{1}$ In the last two decades, a considerable number of 2D metallacycles and 3D metallacages have been reported. ${ }^{2}$ The geometrical shape and size of these supramolecules can be predicted prior to self-assembly based on the 'bite angle' of the organic donor and metal-containing acceptor tecton. ${ }^{2 a, b}$ Several structural motifs [such as ferrocene, carboranes, cavitands, highly aromatic systems (such as anthracene, phenanthrene, perylene, pyrene, etc.), dendrons

\footnotetext{
${ }^{a}$ Department of Chemistry, Indian Institute of Technology Patna, Patna 800013 , Bihar, India.E-mail: neeladri2002@yahoo.co.in,neeladri@iitp.ac.in; Fax: +91612 2277383; Tel: +916122552023

${ }^{b}$ College of Chemistry, Beijing Normal University, Beijing 100875, People's Republic of China

$\dagger$ Electronic supplementary information (ESI) available: ${ }^{1} \mathrm{H}$ and ${ }^{31} \mathrm{P}\left\{{ }^{1} \mathrm{H}\right\} \mathrm{NMR}$ spectra for complexes 1-4 and macrocycles 5 and $\mathbf{6}$. ESI-MS spectra of complexes 1-4. MALDI-TOF-MS spectra and ${ }^{1} \mathrm{H}$ DOSY NMR spectra for macrocycles 5 and 6 . See DOI: $10.1039 / \mathrm{c} 4 \mathrm{qi} 00211 \mathrm{c}$
}

and others] have been incorporated in these self-assembled supramolecules. $^{3}$ This has been achieved by the design of specific modular subunits containing these structural motifs and subsequently using them as tectons in the self-assembly protocol. Additionally, the shape of the supramolecules has been effectively tailored using building blocks of various dimensions.

Triptycene is the smallest member in the class of compounds called iptycenes. Triptycene has a rigid three dimensional framework decorated with three benzene rings in a paddlewheel orientation. Owing to the high level of symmetry associated with its rigid framework, triptycene derivatives have found application in supramolecular chemistry, ${ }^{4}$ material science ${ }^{4}$ and polymer chemistry. ${ }^{5}$ In this context, the use of triptycene motifs as tectons for discrete metallasupramolecular architectures is at a very nascent stage. ${ }^{6}$ A detailed literature search has revealed that only a handful of triptycene-based organometallic complexes have been reported so far. ${ }^{7}$ Consequently, their use in the design of self-assembled metallasupramolecular frameworks has not been explored. Recently, we have reported (for first time) the use of organometallic triptycene derivatives as building blocks in the design of ionic three dimensional discrete supramolecular cages. ${ }^{7 b}$ 
In a continuation of our research efforts towards the synthesis of new triptycene-based donor/acceptor linkers and their use as modified subunits in supramolecular self-assembly, ${ }^{7 a, b}$ herein we report the synthesis of two new triptycene-containing ditopic organoplatinum complexes. Complex 1 was synthesized by the double oxidative-addition of $\mathrm{Pt}\left(\mathrm{PEt}_{3}\right)_{3}$ with dibromotriptycene. ${ }^{8}$ Using the $\sigma$-acetylide synthetic methodology, ${ }^{9}$ the organometallic complex 2 was obtained upon reaction of diethynyltriptycene with trans-bis(triethylphosphine)platinum(II). The halogen atoms (bromine/iodine) in these newly synthesized organometallic complexes ( $\mathbf{1}$ and 2 ) were subsequently exchanged with more labile nitrate anions through a salt metathesis reaction with silver nitrate (3 and $\mathbf{4}$ respectively). All of the new organoplatinum complexes (1-4) have been fully characterized using FT-IR and multinuclear NMR spectroscopies, mass spectrometry and elemental analyses. These ditopic triptycene-based organometallic linkers are structurally rigid with predefined bite angles and thus they have the potential to act as metal-containing acceptor tectons for the construction of discrete metallasupramolecular architectures. To illustrate this point, herein we report the selfassembly of two new platinum(II)-based neutral supramolecular macrocycles (5 and 6) using the triptycene-based organometallic linkers $\mathbf{3}$ and $\mathbf{4}$ as acceptor units and ditopic angular carboxylates as bridging ligands. Macrocycles 5 and $\mathbf{6}$ represent the first examples of triptycene-based neutral metallasupramolecular architectures. These newly synthesized metallasupramolecular macrocycles were completely characterized using multinuclear NMR spectroscopy including ${ }^{1} \mathrm{H}$ DOSY, MALDI-TOF mass spectrometry and elemental analyses. Further insight into the shape and size of the neutral macrocycles was obtained via molecular simulations, employing a PM6 semiempirical molecular orbital method. Theoretical calculations suggest that the dimensions of the metallasupramolecules are in the nanoscalar range.

\section{Results and discussion}

\section{Synthesis and characterization of triptycene-based ditopic organoplatinum acceptor linkers}

Halogenated arenes are one of the most popular classes of synthons utilized in the design and synthesis of metal-containing acceptor building blocks for subsequent use in coordination driven self-assembly processes. ${ }^{10}$ The desired triptycene organoplatinum complex $\mathbf{1}$ was efficiently synthesized by the double oxidative addition $^{8}$ of $\operatorname{Pt}(0)$ to the corres- ponding 2,6-dibromotriptycene ${ }^{11}$ in $66 \%$ yield as shown in Scheme 1.

In the past decade, the design and synthesis of organoplatinum acceptor complexes containing an ethynyl group as a spacer (bridging the central core motif and the peripheral metal center) has attracted the research attention of supramolecular chemists. ${ }^{12}$ Introduction of an ethynyl group imparts rigidity to the resulting linker and simultaneously alters its length, shape and directionality (bite angle). Subsequently, supramolecular tectons/building blocks are derived from these molecules with multiple ethynyl spacers, which in turn are utilized for the self-assembly of exciting nanoscalar macrocycles and cages. $^{12}$

Through the reaction of an appropriate 2,6-diethynyltriptycene $^{5 d}$ with trans- $\mathrm{PtI}_{2}\left(\mathrm{PEt}_{3}\right)_{2}$ in a mixture of toluene (solvent) and triethylamine (base) in the presence of cuprous(I) iodide catalyst, the corresponding di-substituted metal complex 2 was obtained in a good yield (Scheme 2).

The halogen atoms (bromine/iodine) in these newly synthesized organometallic complexes (1 and 2) were subsequently exchanged with more labile nitrate anions through a salt metathesis reaction with silver nitrate. The nitrate salts (3 and 4) were obtained in excellent yields (Schemes 1 and 2). These triptycene-organoplatinum complexes are white coloured solids that are stable in air/moisture with a high solubility in common organic solvents. The FTIR spectra of complexes 2 and 4 exhibit intense peaks at $2111 \mathrm{~cm}^{-1}$ and $2121 \mathrm{~cm}^{-1}$ respectively, due to the ethynyl functional group. The ${ }^{1} \mathrm{H}$ NMR spectra also suggest the formation of the desired organometallic complexes due to the appearance of a singlet peak between 5.06 and 5.31 ppm corresponding to the bridgehead protons in complexes 1-4 (ESI $\dagger$ ). As expected, the appearance of peaks in the range of $\delta=0.95$ to $2.20 \mathrm{ppm}$ for complexes 1-4 is attributed to the ethyl group of the $\mathrm{PEt}_{3}$ units bound to the $\mathrm{Pt}$ (II) centers. Organometallic complexes were also characterized using ${ }^{31} \mathrm{P}\left\{{ }^{1} \mathrm{H}\right\}$ NMR spectroscopy (ESI $\dagger$ ). The ${ }^{31} \mathrm{P}\left\{{ }^{1} \mathrm{H}\right\}$ NMR spectra of both of the halogenated complexes 1 and 2 show a sharp singlet at 12.39 and 8.56 ppm respectively with concomitant ${ }^{195} \mathrm{Pt}$ satellites $\left({ }^{1} J_{\mathrm{PPt}}=1383 \mathrm{~Hz}\right.$ for 1 and $1166 \mathrm{~Hz}$ for 2 ). In the case of the nitrate salts 3 and 4 , the ${ }^{31} \mathrm{P}$ resonance due to the phosphine group shows a downfield shift in its peak position compared to those of the singlets observed for the corresponding halo analogues, appearing at $18.23 \mathrm{ppm}$ $\left({ }^{1} J_{\mathrm{PPt}}=1453 \mathrm{~Hz}\right)$ and $20.19 \mathrm{ppm}\left({ }^{1} J_{\mathrm{PPt}}=1244 \mathrm{~Hz}\right)$ respectively. These chemical shifts observed in the ${ }^{31} \mathrm{P}\left\{{ }^{1} \mathrm{H}\right\}$ NMR are in the expected range for a trans $-\mathrm{PtP}_{2}$ system connected to arene $^{8}$ and ethynyl moieties. ${ }^{9}$ In the ${ }^{31} \mathrm{P}$ NMR of complexes 1

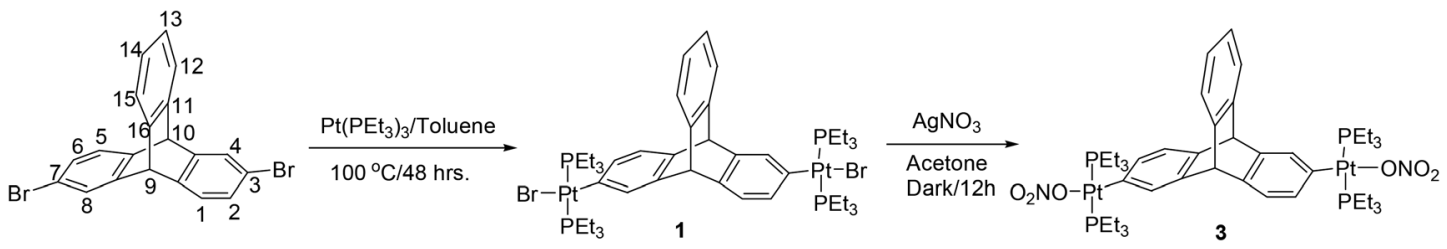

Scheme 1 Synthesis of the triptycene-based organoplatinum complexes 1 and 3 . 


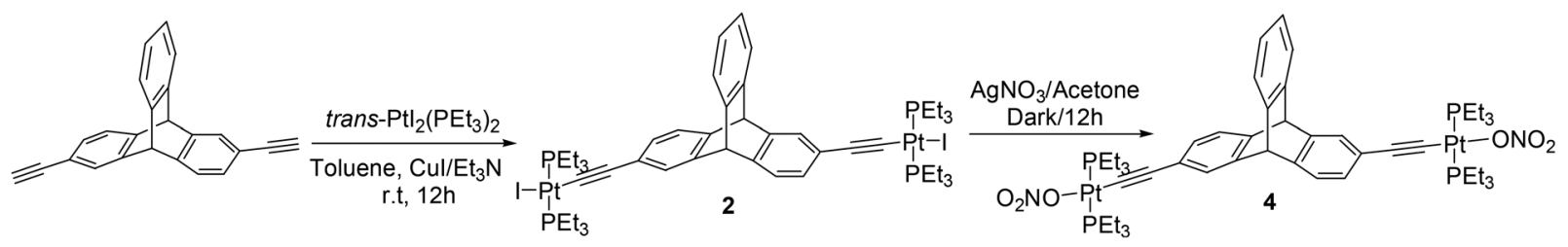

Scheme 2 Synthesis of the triptycene-based organoplatinum complexes 2 and 4 .

and 2, the appearance of a single sharp singlet also suggests that the phosphine groups are chemically equivalent with a trans orientation of the phosphine groups at the square planar $\mathrm{Pt}$ (II) centre. The formation of complexes 1-4 was further confirmed from mass spectrometry (ESI-MS) analyses and elemental analyses (ESI $\dagger$ ).

\section{Self assembly of 2D macrocycles}

The triptycene-based organoplatinum complexes $\mathbf{3}$ and $\mathbf{4}$ are ditopic (having two reactive sites) moieties and hence they are potential acceptor tectons that may be reacted with appropriate ditopic donor ligands to yield metallamacrocycles via a coordination driven self-assembly reaction. In order to test this hypothesis, an acetone solution of 3 was reacted with an aqueous solution of disodium terephthalate in a $1: 1$ stoichiometric ratio at ambient temperature (Scheme 3). This resulted in the gradual precipitation of the neutral assembly 5 as a white solid, which upon washing (with water) and recrystallization (from chloroform) yielded a white microcrystalline solid (81\% isolated yield). The product obtained from this selfassembly reaction is highly soluble in common organic solvents such as DCM, chloroform, ethanol, methanol and THF.

The product thus obtained was subjected to NMR spectroscopic analysis to ascertain its composition. The ${ }^{31} \mathrm{P}\left\{{ }^{1} \mathrm{H}\right\}$ spectrum of the product recorded in $\mathrm{CDCl}_{3}$, exhibited a sharp singlet ( $\delta 16.14 \mathrm{ppm})$ with accompanying ${ }^{195} \mathrm{Pt}$ satellites $\left({ }^{1} J_{\mathrm{PPt}}\right.$ $=1459 \mathrm{~Hz}$ ) shifted upfield relative to the precursor acceptor linker 3 by 2 ppm, suggesting the formation of a highly symmetrical self-assembled species in which all of the phosphorous atoms are chemically equivalent (Fig. 1a). The shift in the peak position of the ${ }^{31} \mathrm{P} \mathrm{NMR}$ signal is a clear indication of a new metal-ligand coordination. The ${ }^{1} \mathrm{H}$ NMR spectrum of the product (Fig. 1b) also suggested the incorporation of both terephthalate (the sharp singlet at $7.96 \mathrm{ppm}$ is assigned to protons on the phenyl ring of the terephthalate unit) and triptycene motifs (peaks at $5.07 \mathrm{ppm}$ due to the bridgehead proton). Integration of the ${ }^{1} \mathrm{H}$ peaks corresponding to terephthalate and that due to the triptycene motif suggests the presence of these two tectons in a 1:1 stoichiometric ratio. Thus coordination between a triptycene containing $\mathrm{Pt}^{\mathrm{II}}{ }_{2}$ unit and a terephthalate is confirmed from the multinuclear NMR spectra of the product. Additionally, this organometallic macrocycle (5) possesses a single trace in the ${ }^{1} \mathrm{H}$ DOSY NMR (ESI $\dagger$ ), indicating the formation of a single product and thereby ruling out the presence of additional species such as other macrocycles or oligomers in solution.

However, the NMR spectroscopy technique does not predict the number of each unit (organometallic acceptor/organic donor) present in the self-assembled product. In such a situation, mass spectrometry is utilized as a powerful tool to interpret the composition of the macrocyclic product. In the present case, MALDI-TOF-MS spectrometric analysis confirmed the actual composition of macrocycle 5 (ESI $\dagger$ ). The MALDI-TOF-MS spectrum of 5 showed two peaks at $m / z=$

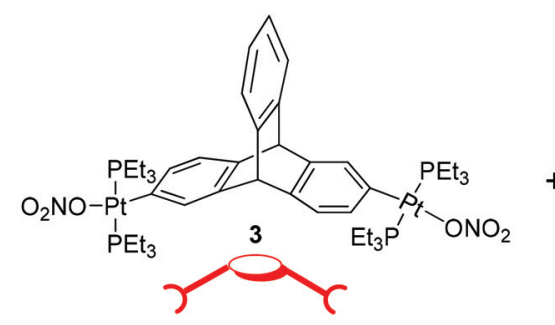

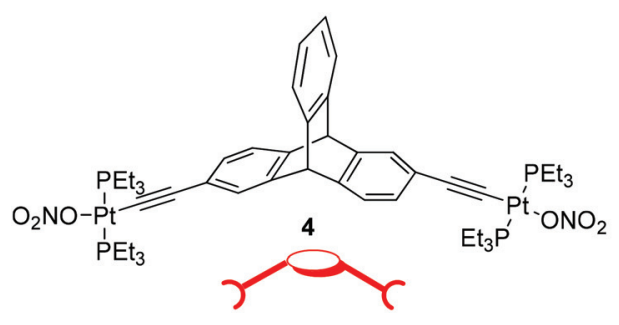
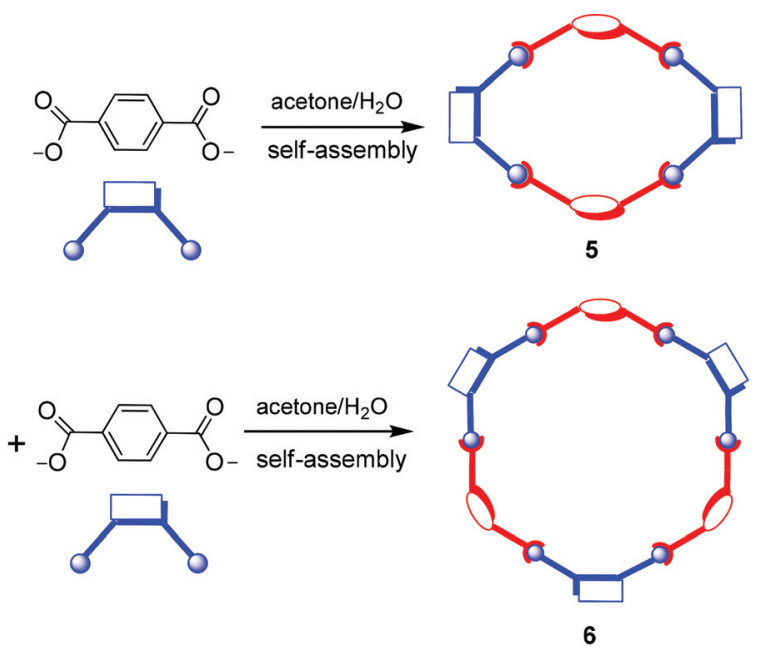

Scheme 3 Synthesis of the molecular macrocycles 5 and 6 . 

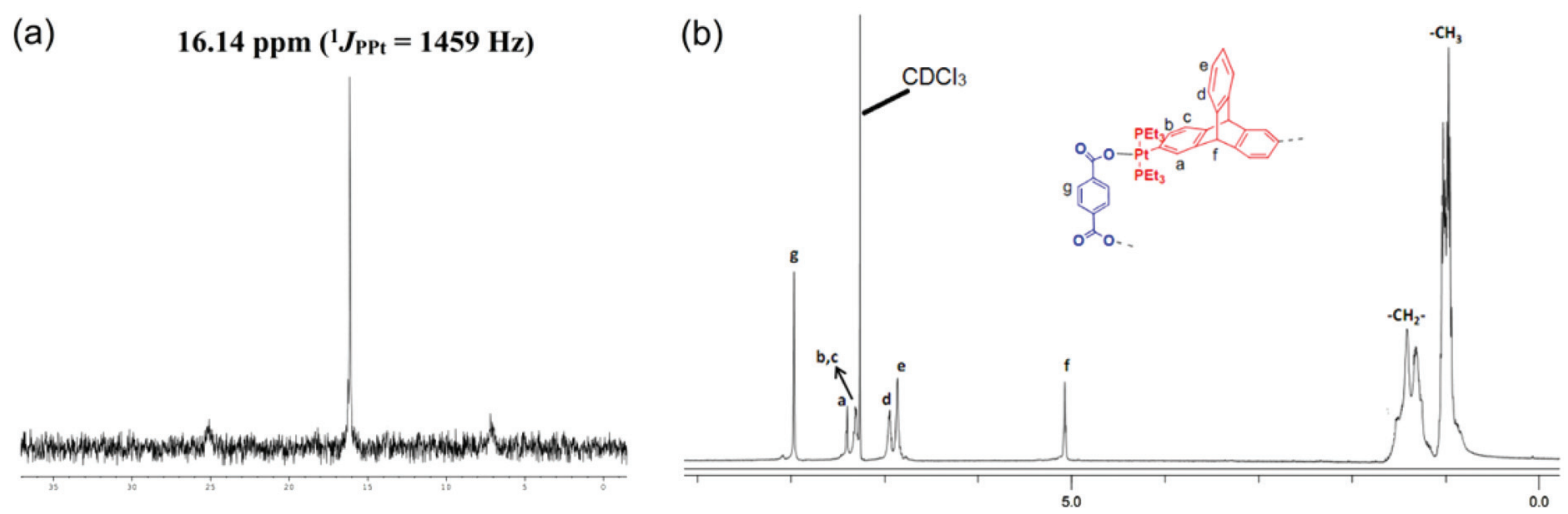

Fig. 1 (a) The ${ }^{31} \mathrm{P}\left\{{ }^{1} \mathrm{H}\right\}$ NMR and (b) ${ }^{1} \mathrm{H}$ NMR spectra of macrocycle 5 in $\mathrm{CDCl}_{3}$.

2560.9 and $m / z=2582.9$ corresponding to the $[2+2+\mathrm{H}]^{+}$and $[2+2+\mathrm{Na}]^{+}$species respectively, assuming a $[2+2]$ self-assembly between two units each of a triptycene-containing $\mathrm{Pt}^{\mathrm{II}}{ }_{2}$ unit and a terephthalate. These signals were isotopically resolved (Fig. 2a) and these are in good agreement with theoretically calculated isotopic distribution patterns, assuming a $[2+2]$ self-assembled macrocycle.

Both organometallic complexes $\mathbf{3}$ and $\mathbf{4}$ have a central triptycene core and contain two $\mathrm{Pt}(\mathrm{II})$ acceptor centers (with the same predefined bite angle). Moreover, in both 3 and $\mathbf{4}$, the same phosphine ligands are attached to the $\mathrm{Pt}(\mathrm{II})$ center. However, the latter is longer in length than the former, because of the presence of the ethynyl spacer groups in $\mathbf{4}$ that bridge the triptycene core and the peripheral Pt(II) centers. Reaction of the acceptor linker $\mathbf{4}$ with disodium terephthalate proceeded in a similar manner to that described for 3 , yielding a white microcrystalline solid (6, isolated yield $78 \%$ ). ${ }^{1} \mathrm{H}$ and ${ }^{31} \mathrm{P}\left\{{ }^{1} \mathrm{H}\right\}$ NMR (ESI $\dagger$ ) of the product suggested the incorporation
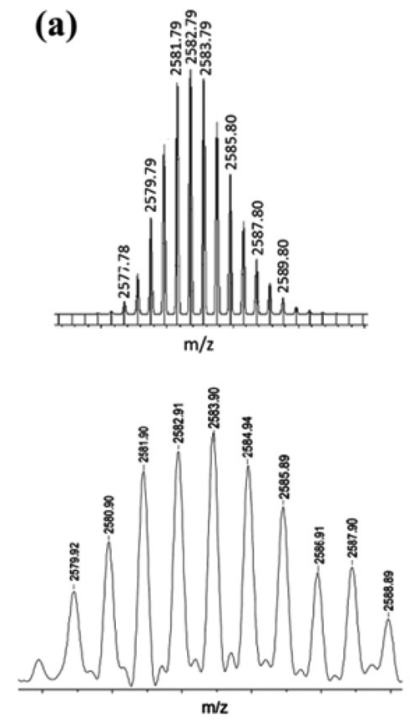

Fig. 2 Theoretical (top) and experimental (bottom) MALDI-TOF-MS spectra of (a) macrocycle 5 and (b) macrocycle 6. of both of the subunits (the organometallic triptycene-based acceptor unit and the terephthalate) as well as the formation of a highly symmetrical product (a sharp ${ }^{31} \mathrm{P}$ singlet at $18.30 \mathrm{ppm}$ with concomitant Pt satellites; ${ }^{1} J_{\mathrm{PPt}}=1258 \mathrm{~Hz}$ ). Furthermore, a single diffusion coefficient in the ${ }^{1} \mathrm{H}$ DOSY NMR spectrum points towards the formation of a single product and rules out the possibility of an oligomeric species in the solution (ESI $\dagger$ ). In this case also, the product obtained was subjected to MALDI-TOF-MS analysis to identify its composition. MALDI-TOF-MS analysis of 6 exhibited the formation of a [3+3] macrocycle due the presence of a peak at $\mathrm{m} / \mathrm{z}=4001.4$ corresponding to a $[3+3+\mathrm{Na}]^{+}$species. This peak $(\mathrm{m} / \mathrm{z}=$ 4001.4) was also isotopically resolved and was found to be in good agreement with its theoretical distribution (Fig. 2b). Interestingly, in this case, evidence for the formation of the $[2+2]$ self-assembled product was not observed from MALDITOF-MS spectrometric studies. This is evident from the absence of molecular ion peaks for the [2+2] adducts at $\mathrm{m} / \mathrm{z}=$ $2653.8[2+2+\mathrm{H}]^{+}$and $2675.7[2+2+\mathrm{Na}]^{+}$from MALDITOF-MS analysis. Thus, mass spectrometric studies indicated that the use of a longer acceptor tecton (4) results in the formation of a [3 + 3] self-assembled metallamacrocycle, while a relatively smaller acceptor tecton (3) yields a [2+2] supramolecular framework (Scheme 3).

All of our attempts to obtain X-ray quality single crystals in the case of the self-assembled macrocycles $\mathbf{5}$ and $\mathbf{6}$ were unsuccessful. However, to explain the observed difference in composition of the self-assembled products upon the use of acceptor linkers of different sizes, thermodynamic parameters of the dimeric and the trimeric adducts were calculated using a PM6 semiempirical molecular orbital method. ${ }^{13}$ On comparing the $[2+2]$ and $[3+3]$ metallacycles, it is known that the formation of the $[3+3]$ adduct is entropically disfavored, as a smaller number of molecular ensembles would result compared to the number of $[2+2]$ macrocycles that can be generated using the same number of building blocks. ${ }^{14}$ Therefore, in the case of linker 4 , the anomalous formation of the [3+3] self-assembled macrocycle 6 over the entropically more preferable $[2+2]$ product can be explained by comparing the stabilization energy which is brought by a single monomer of the adduct. 

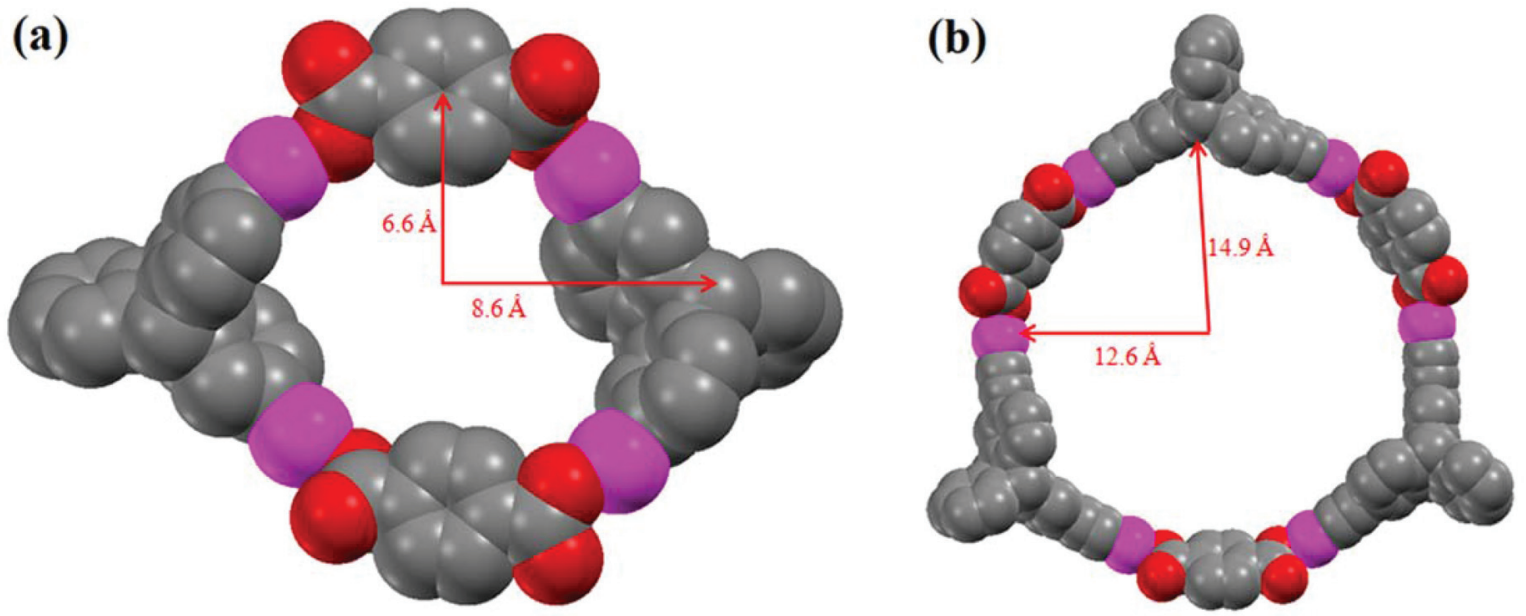

Fig. 3 Simulated spacefill molecular models of (a) macrocycle 5 and (b) macrocycle 6 optimized using PM6 semiempirical molecular orbital methods. The phosphine ligands and $\mathrm{H}$ atoms are omitted for clarity (grey: $\mathrm{C}$, red: $\mathrm{O}$, pink: Pt).

The energy (heat of formation) optimization, calculated using the PM6 semiempirical molecular orbital method, reveals that for linker 4, the stabilization energy for a single monomer of the $[3+3]$ adduct is $E_{[3+3]} / 3=(-1656.64 / 3)=-552.21 \mathrm{~kJ} \mathrm{~mol}^{-1}$. On the other hand, in the case of the $[2+2]$ adduct, the stabilization energy of the single monomer is $E_{[2+2]} / 2=(-981.50 / 2)=$ $-490.75 \mathrm{~kJ} \mathrm{~mol}^{-1}$. Therefore in case of the $[3+3]$ adduct, the stabilization energy which is brought by a single monomer of the adduct is higher than that of the [2+2] adduct by $61.46 \mathrm{~kJ}$ $\mathrm{mol}^{-1}$. This energy calculation strongly supports the observed formation of a $[3+3]$ macrocycle over a $[2+2]$ structure in the case of linker 4 as indicated from MALDI-TOF-MS analysis. Additionally, the geometries of the macrocycles $\mathbf{5}$ and $\mathbf{6}$ were also optimized using PM6 molecular orbital methods. The internal dimensions of the macrocycles $\mathbf{5}$ and $\mathbf{6}$ are depicted in Fig. 3. The geometry optimization of macrocycles $\mathbf{5}$ and $\mathbf{6}$ reveals that in both cases, the platinum centers display slightly distorted square planar geometries resulting from the coordination of oxygen atoms of the dicarboxylate ligands.

\section{Conclusions}

In summary, we report the synthesis of two new triptycenebased organoplatinum complexes containing two $\mathrm{Pt}(\mathrm{II})$ centers in reasonably good yields. In these complexes, the triptycene core is either $\sigma$-bonded to the peripheral bis(transtrialkylphosphine)platinum units directly or via a bridging ethynyl spacer unit. These triptycene-containing ditopic $\mathrm{Pt}^{\mathrm{II}}{ }_{2}$ organometallic complexes and their corresponding nitrate salts were characterized using FT-IR, multinuclear NMR spectroscopy, mass spectrometry and elemental analyses. The presence of a triptycene or ethynyltriptycene backbone imparts rigidity to these organometallic complexes. Moreover, the separation of the $\mathrm{Pt}(\mathrm{II})$ centers has been spatially tuned by the inclusion or exclusion of ethynyl groups. Further, the potential of these organometallic tectons as supramolecular acceptor synthons in coordination driven self-assembly protocols has been tested/explored. In this regard, two neutral nanoscalar metallamacrocycles (5 and 6) have been constructed using these triptycene-based organoplatinum complexes in conjugation with a dicarboxylate anion (terephthalate). Multinuclear NMR spectroscopy, including ${ }^{1} \mathrm{H}$ DOSY, of these supramolecules (5 and $\mathbf{6}$ ) ruled out the formation of multiple oligomeric species and suggested the formation of single highly symmetrical discrete moieties. The chemical compositions of these macrocycles were determined from mass spectrometric (MALDI-TOF-MS) analysis, which indicated the formation of a $[3+3]$ self-assembled metallamacrocycle $(6)$ in cases where the longer acceptor linker 4 was used, while the use of the relatively short linker 3 yields the $[2+2]$ supramolecular framework 5 . The formation of the entropically disfavoured [3+3] self-assembled adduct in the case of linker 4 was further supported by results obtained from computational calculations. The comparison of the stabilization energies, optimized using the PM6 semiempirical molecular orbital method, suggests the preferential formation of the $[3+3]$ adduct over the corresponding $[2+2]$ adduct in the case of linker 4 as experimentally observed from MALDI-TOF-MS analysis. The shapes and dimensions of these nanoscalar frameworks were also predicted from molecular simulations using PM6 semiempirical molecular orbital methods. To the best of our knowledge, the self-assembled macrocycles 5 and $\mathbf{6}$ are unique examples of triptycene-based neutral "platinamacrocycles" to date. To summarize, a facile and efficient synthetic protocol for the construction of neutral metallasupramolecular frameworks containing a triptycene motif has been described. Additionally, the effect of changing the dimension of the triptycene-based acceptor building blocks on the shape and size of the resulting supramolecular framework was studied. Triptycene-based organometallic acceptors, as described in this manuscript, have immense potential for the design of new self-assembled 
Supramolecular Coordination Complexes (SCCs) and MetalOrganic Frameworks (MOFs). The platinamacrocycles reported in the literature are known to be very stable and have several applications in terms of host-guest chemistry. Due to the presence of the large void space in their cavities, the newly synthesized platinamacrocycles reported herein may also have interesting host-guest properties. Studies are currently being undertaken in our laboratory in this direction.

\section{Experimental section}

\section{General details}

All of the chemicals and anhydrous solvents used in this work were purchased from commercial sources and were used without further purification. 2,6-Dibromotriptycene, ${ }^{11}$ 2,6diethynyltriptycen $^{5 d}$ and tris(triethylphosphine)platinum $(0)^{15}$ were prepared by following reported literature procedures. FTIR spectra were recorded using a PerkinElmer Spectrum 400 FT-IR spectrophotometer. ${ }^{1} \mathrm{H}$ and ${ }^{31} \mathrm{P}$ NMR spectra were recorded using Bruker 400 or $500 \mathrm{MHz}$ spectrometers. Elemental analyses were carried out using a Thermo Scientific Flash 2000 Organic Elemental Analyzer. MALDI-TOF-MS spectra of the compounds were recorded using a Bruker UltrafleXtreme ${ }^{\mathrm{TM}}$ MALDI-TOF/TOF mass spectrometer. DOSY NMR measurements were performed using a Bruker AV 500 NMR spectrometer with a $5 \mathrm{~mm}$ gradient probe at $298 \mathrm{~K}$. DOSY experiments were done using a standard Bruker pulse sequence (ledbpgp2s) with a longitudinal eddy current delay.

Synthesis of 2,6-bis(trans-Pt $\left.\left(\mathrm{PEt}_{3}\right)_{2} \mathrm{Br}\right)$ triptycene (1). To a $25 \mathrm{ml}$ Schlenk flask containing one equiv. of 2,6-dibromotriptycene (38 mg, $0.09 \mathrm{mmol}$ ) and four equiv. of $\mathrm{Pt}\left(\mathrm{PEt}_{3}\right)_{3}$ (200 $\mathrm{mg}, 0.364 \mathrm{mmol}$ ), $10 \mathrm{ml}$ of dry toluene was added in a glove box. The reaction mixture was stirred for $48 \mathrm{~h}$ at $100{ }^{\circ} \mathrm{C}$ under nitrogen. The resulting light yellow coloured solution was evaporated to dryness under vacuum using a rotary evaporator. The yellow coloured residue thus obtained was purified by column chromatography over silica gel eluting with DCMhexane $(2.5: 1$, up to $9: 1, \mathrm{v} / \mathrm{v})$ affording the pure organometallic complex 1 as a white solid.

Yield: $84 \mathrm{mg}, 71 \%$, mp 237-238 ${ }^{\circ} \mathrm{C} ;{ }^{1} \mathrm{H} \mathrm{NMR}\left(\mathrm{CDCl}_{3}\right.$, $400 \mathrm{MHz}): \delta 1.13-1.22\left(\mathrm{~m}, 36 \mathrm{H},-\mathrm{CH}_{3}\right), 1.48-1.57(\mathrm{~m}, 24 \mathrm{H}$, $-\mathrm{CH}_{2}-$ ) 5.06 (s, 2H, -CH), 6.82-6.93 (m, 6H, Ar-H), 7.26-7.29 $(\mathrm{m}, 2 \mathrm{H}, \mathrm{Ar}-\mathrm{H}), 7.32-7.33(\mathrm{~m}, 2 \mathrm{H}, \mathrm{Ar}-\mathrm{H}) .{ }^{31} \mathrm{P} \mathrm{NMR}\left(\mathrm{CDCl}_{3}\right.$, $162 \mathrm{MHz}): \delta 12.39\left({ }^{1} J_{\mathrm{PPt}}=1383 \mathrm{~Hz}\right) . \mathrm{IR}(\mathrm{KBr}): 2961,2925$, 2876, 2852, 1585, 1450, 1413, 1378, 1255, 1240, 1168, 1035, 848, 764, $742 \mathrm{~cm}^{-1}$. Anal. Calcd For $\mathrm{C}_{44} \mathrm{H}_{72} \mathrm{Br}_{2} \mathrm{P}_{4} \mathrm{Pt}_{2}$ : C, 41.45; $\mathrm{H}$, 5.69. Found: $\mathrm{C}, 41.57$; H, 5.81. ESI-MS: $\mathrm{m} / \mathrm{z}$ calcd for $[\mathrm{M}-\mathrm{Br}]^{+}:$1193.3, found 1194.29.

Synthesis of 2,6-bis(trans-Pt $\left.\left(\mathrm{PEt}_{3}\right)_{2} \mathrm{I}\right)$ ethynyltriptycene (2). One equiv. of 2,6-diethynyltriptycene $(27.7 \mathrm{mg}, 0.092 \mathrm{mmol})$ and four equiv. of trans-diiodobis(triethylphosphine)platinum (252 mg, $0.368 \mathrm{mmol}$ ) were charged in a $25 \mathrm{ml}$ Schlenk flask in a glove box. Subsequently, $12 \mathrm{ml}$ of dry toluene and $4 \mathrm{ml}$ of freshly distilled triethylamine were added under nitrogen. The solution was stirred for $10 \mathrm{~min}$ at room temperature before the addition of 0.2 equiv. of $\mathrm{CuI}$ in one portion. After overnight stirring at room temperature, triethylammonium iodide precipitated out from the solution, which was separated by filtration. The toluene was evaporated using a rotary evaporator and the resulting yellow residue was purified by column chromatography on silica gel eluting with $3 \%$ ethyl acetate in hexane first and then increasing this to $6 \%$ ethyl acetate in hexane to isolate complex 2 as a white solid.

Yield: $83 \mathrm{mg}, 64 \%$, mp 240-242 ${ }^{\circ} \mathrm{C} ;{ }^{1} \mathrm{H}$ NMR $\left(\mathrm{CDCl}_{3}\right.$, $400 \mathrm{MHz}): \delta 1.09-1.73\left(\mathrm{~m}, 36 \mathrm{H},-\mathrm{CH}_{3}\right), 2.14-2.20(\mathrm{~m}, 24 \mathrm{H}$, $\left.-\mathrm{CH}_{2}-\right), 5.29(\mathrm{~s}, 2 \mathrm{H},-\mathrm{CH}), 6.90(\mathrm{dd}, J=7.6, J=1.2,2 \mathrm{H}, \mathrm{Ar}-\mathrm{H})$, 6.96-6.99 (m, 2H, Ar-H), 7.20-7.22 (d, $J=7.6,2 \mathrm{H}, \mathrm{Ar}-\mathrm{H}), 7.25$ (s, 2H, Ar-H), 7.34-7.36 (m, 2H, Ar-H). ${ }^{31} \mathrm{P} \mathrm{NMR}\left(\mathrm{CDCl}_{3}\right.$, $162 \mathrm{MHz}): \delta 8.56\left({ }^{1} J_{\mathrm{PPt}}=1166 \mathrm{~Hz}\right)$. IR $(\mathrm{KBr}): 3061,2961,2930$, 2874, 2111, 1610, 1465, 1409, 1376, 1251, 1031, 767, $742 \mathrm{~cm}^{-1}$. Anal. Calcd For $\mathrm{C}_{48} \mathrm{H}_{72} \mathrm{I}_{2} \mathrm{P}_{4} \mathrm{Pt}_{2}$ : C, 40.69; H, 5.12. Found: C, 40.82; H, 5.26. ESI-MS: $m / z$ calcd for $[\mathrm{M}-\mathrm{I}]^{+}: 1289.28$, found 1289.00 .

Synthesis of complexes 3 and 4. To a stirred solution of complex 1 or $2(0.03 \mathrm{mmol})$ in chloroform, $\mathrm{AgNO}_{3}(10.2 \mathrm{mg}$, $0.06 \mathrm{mmol}$ ) was added in one portion. The reaction mixture was stirred overnight in the dark at room temperature. The resulting yellow silver halide precipitate was filtered through a bed of celite and the filtrate was evaporated to dryness to obtain the corresponding nitro complex $\mathbf{3}$ or $\mathbf{4}$ as a white solid.

Complex 3. Yield: $35 \mathrm{mg}$, 94\%, mp 234-236 ${ }^{\circ} \mathrm{C} ;{ }^{1} \mathrm{H}$ NMR $\left(\mathrm{CDCl}_{3}, 400 \mathrm{MHz}\right): \delta$ 0.95-1.09 (m, 36H, $\left.-\mathrm{CH}_{3}\right), 1.24-1.46(\mathrm{~m}$, $\left.24 \mathrm{H},-\mathrm{CH}_{2}-\right), 5.10(\mathrm{~s}, 2 \mathrm{H},-\mathrm{CH}), 6.78$ (d, $\left.J=7.6 \mathrm{~Hz}, 2 \mathrm{H}, \mathrm{Ar}-\mathrm{H}\right)$, $6.86(\mathrm{~d}, J=7.2,2 \mathrm{H}, \mathrm{Ar}-\mathrm{H}), 6.95-6.98(\mathrm{~m}, 2 \mathrm{H}, \mathrm{Ar}-\mathrm{H}), 7.30-7.32$ $(\mathrm{m}, 4 \mathrm{H}, \mathrm{Ar}-\mathrm{H}) \cdot{ }^{31} \mathrm{P} \mathrm{NMR}\left(\mathrm{CDCl}_{3}, 162 \mathrm{MHz}\right): \delta 18.23\left({ }^{1} J_{\mathrm{PPt}}=\right.$ $1453 \mathrm{~Hz}$ ). IR (KBr): 2962, 2925, 2875, 2853, 1585, 1465, 1444, 1376, 1276, 1237, 1034, 997, 765, $738 \mathrm{~cm}^{-1}$. Anal. Calcd For $\mathrm{C}_{44} \mathrm{H}_{72} \mathrm{~N}_{2} \mathrm{O}_{6} \mathrm{P}_{4} \mathrm{Pt}_{2}$ : C, 44.79; H, 5.64; N, 2.18. Found: C, 44.92; $\mathrm{H}, 5.74 ; \mathrm{N}, 2.25$. ESI-MS: $m / z$ Calcd for $\left[\mathrm{M}-\mathrm{NO}_{3}\right]^{+}: 1176.37$, Found: 1176.13.

Complex 4. Yield: $36 \mathrm{mg}$, 93\%, mp 204-206 ${ }^{\circ} \mathrm{C} ;{ }^{1} \mathrm{H}$ NMR $\left(\mathrm{CDCl}_{3}, 500 \mathrm{MHz}\right): \delta 1.15-1.21\left(\mathrm{~m}, 36 \mathrm{H},-\mathrm{CH}_{3}\right), 1.87-1.93(\mathrm{~m}$, $\left.24 \mathrm{H},-\mathrm{CH}_{2}-\right), 5.31$ (s, 2H, $\left.-\mathrm{CH}\right), 6.87$ (d, $\left.J=7.2 \mathrm{~Hz}, 2 \mathrm{H}, \mathrm{Ar}-\mathrm{H}\right)$, 6.99-7.00 (m, 2H, Ar-H), 7.21-7.23 (m, 4H, Ar-H), 7.35-7.37 $(\mathrm{m}, 2 \mathrm{H}, \mathrm{Ar}-\mathrm{H}) .{ }^{31} \mathrm{P}$ NMR $\left(\mathrm{CDCl}_{3}, 202 \mathrm{MHz}\right): \delta 20.19\left({ }^{1} J_{\mathrm{PPt}}=\right.$ $1244 \mathrm{~Hz}$ ). IR (KBr): 2966, 2932, 2877, 2121, 1476, 1467, 1384, 1277, 1036, 989, 768, $743 \mathrm{~cm}^{-1}$. Anal. Calcd For $\mathrm{C}_{48} \mathrm{H}_{72} \mathrm{~N}_{2} \mathrm{O}_{6} \mathrm{P}_{4} \mathrm{Pt}_{2}$ : C, 41.29; H, 5.64; N, 2.33. Found: C, 41.37; $\mathrm{H}, 5.71 ; \mathrm{N}, 2.4$. ESI-MS: $\mathrm{m} / z$ Calcd for $\left[\mathrm{M}-\mathrm{NO}_{3}\right]^{+}: 1224.37$, Found: 1224.40 .

Synthesis of the 2D macrocycles 5 and 6. To a $2 \mathrm{~mL}$ acetone solution containing $0.015 \mathrm{mmol}$ of dinitrate ( 3 or 4 ), a $0.5 \mathrm{~mL}$ aqueous solution of disodium terephthalate $(0.015 \mathrm{mmol})$ was added dropwise with continuous stirring ( $5 \mathrm{~min}$ ), whereupon a white product precipitated. This was centrifuged, washed several times with water and subsequently dried under vacuum. The product was collected, recrystallized from chloroform and washed with ether to obtain the macrocycle 5 or $\mathbf{6}$ as a white microcrystalline solid.

Macrocycle 5. Yield $13.7 \mathrm{mg}, 81 \% ;{ }^{1} \mathrm{H}$ NMR $\left(\mathrm{CDCl}_{3}\right.$, $500 \mathrm{MHz}): \delta$ 0.95-1.04 (m, 72H, $\left.-\mathrm{CH}_{3}\right), 1.30-1.53(\mathrm{~m}, 48 \mathrm{H}$, 
$\left.-\mathrm{CH}_{2}-\right), 5.07(\mathrm{~s}, 4 \mathrm{H},-\mathrm{CH}), 6.86(\mathrm{~s}, 4 \mathrm{H}, \mathrm{Ar}-\mathrm{H}), 6.94-6.95(\mathrm{~m}, 8 \mathrm{H}$, $\mathrm{Ar}-\mathrm{H}$ ), 7.30-7.31 (m, 4H, Ar-H), 7.39 (s, 4H, Ar-H), 7.96 (s, 8H, $\mathrm{Ar}-\mathrm{H}) .{ }^{31} \mathrm{P}$ NMR $\left(\mathrm{CDCl}_{3}, 162 \mathrm{MHz}\right): \delta 16.14\left({ }^{1} J_{\mathrm{PPt}}=1459 \mathrm{~Hz}\right)$. Anal. Calcd For $\mathrm{C}_{104} \mathrm{H}_{152} \mathrm{O}_{8} \mathrm{P}_{8} \mathrm{Pt}_{4}: \mathrm{C}, 48.82 ; \mathrm{H}, 5.99$. Found: C, 48.65; H, 6.13. IR (KBr): 2963, 2929, 2877, 1611, 1454, 1413, 1378, 1330, 1253, 1034, 821, 766, $743 \mathrm{~cm}^{-1}$. MALDI-TOF-MS: $\mathrm{m} / \mathrm{z}$ Calcd for $[\mathrm{M}+\mathrm{H}]^{+}:$2560.81, Found: 2560.9 and Calcd for $[\mathrm{M}+\mathrm{Na}]^{+}:$2582.79, Found: 2582.9.

Macrocycle 6. Yield $13.76 \mathrm{mg}, 78 \% ;{ }^{1} \mathrm{H}$ NMR $\left(\mathrm{CDCl}_{3}\right.$, $500 \mathrm{MHz}): \delta$ 1.14-1.19 (m, 108H, $\left.-\mathrm{CH}_{3}\right), 1.87-1.90(\mathrm{~m}, 72 \mathrm{H}$, $-\mathrm{CH}_{2}-$ ), 5.28 (s, 6H, $\left.-\mathrm{CH}\right), 6.85$ (d, $\left.J=7.5 \mathrm{~Hz}, 6 \mathrm{H}, \mathrm{Ar}-\mathrm{H}\right)$, 6.96-6.97 (m, 6H, Ar-H), 7.20-7.21 (m, 12H, Ar-H), 7.33-7.35 $(\mathrm{m}, 6 \mathrm{H}, \mathrm{Ar}-\mathrm{H}), 7.95(\mathrm{~s}, 12 \mathrm{H}, \mathrm{Ar}-\mathrm{H}) .{ }^{31} \mathrm{P} \mathrm{NMR}\left(\mathrm{CDCl}_{3}\right.$, $162 \mathrm{MHz}): \delta 18.30\left({ }^{1} J_{\mathrm{PPt}}=1258 \mathrm{~Hz}\right)$. Anal. Calcd For $\mathrm{C}_{168} \mathrm{H}_{228} \mathrm{O}_{12} \mathrm{P}_{12} \mathrm{Pt}_{6}$ : C, 50.68; H, 5.77. Found: C, 50.45; H, 5.91. IR (KBr): 2963, 2926, 2877, 2851, 2114, 1625, 1465, 1377, 1328, 1034, 822, 766, $742 \mathrm{~cm}^{-1}$. MALDI-TOF-MS: $\mathrm{m} / \mathrm{z}$ Calcd for $[\mathrm{M}+$ $\mathrm{Na}]^{+}:$4001.19, Found: 4001.4 .

\section{Authors' contributions}

N.D. and S.C. conceived the research idea. S.C. synthesized all of the new triptycene-based organometallic complexes and the neutral metallacycles reported in this manuscript. S.B. assisted in the synthesis of some of the literature reported triptycene precursors. J.M. and H.T. optimized the energy minimized geometry of the metallacycles 5 and 6 using the PM6 semiempirical molecular modeling method. All of the authors have contributed to compiling the manuscript and have approved the final manuscript.

\section{Acknowledgements}

N.D. thanks the Department of Science and Technology, Govt. of India, New Delhi (DST no: SR/FT/CS-028/2009) and the Indian Institute of Technology Patna for financial support. The authors acknowledge Dr P.R. Rajamohanan, Central NMR Facility, CSIR-NCL, Pune for recording DOSY NMR spectra. The authors also acknowledge Dr Sivaramaiah Nallapeta (Bruker Daltonics India) for MALDI-TOF mass spectrometric data. S.C. and S.B. thank IIT Patna for an Institute Research Fellowship. The authors acknowledge SAIF-Panjab University and SID, IISc Bangalore for providing analytical facilities.

\section{References}

1 (a) J. W. Steed, D. R. Turner and K. J. Wallace, Core Concepts in Supramolecular Chemistry and Nano chemistry, Wiley, West Sussex, UK, 2007; (b) J.-M. Lehn, Proc. Natl. Acad. Sci. U. S. A., 2002, 99, 4763; (c) J. W. Steed and J. L. Atwood, Supramolecular Chemistry, John Wiley \& Sons, Ltd, United Kingdom, 2009; (d) M. Fujita, D. Oguro, M. Miyazawa, H. Oka, K. Yamaguchi and K. Ogura, Nature, 1995, 378,
469; (e) B. Olenyuk, J. A. Whiteford, A. Fechtenkotter and P. J. Stang, Nature, 1999, 398, 796; $(f)$ K. N. Raymond, Nature, 2009, 460, 585.

2 (a) T. R. Cook, Y.-R. Zheng and P. J. Stang, Chem. Rev., 2013, 113, 734; (b) R. Chakrabarty, P. S. Mukherjee and P. J. Stang, Chem. Rev., 2011, 111, 6810; (c) M. D. Pluth, R. G. Bergman and K. N. Raymond, Acc. Chem. Res., 2009, 42, 1650; (d) M. Yoshizawa and M. Fujita, Bull. Chem. Soc. Jpn., 2010, 83, 609; (e) M. Yoshizawa, J. K. Klosterman and M. Fujita, Angew. Chem., Int. Ed., 2009, 48, 3418; (f) C. G. Oliveri, P. A. Ulmann, M. J. Wiester and C. A. Mirkin, Acc. Chem. Res., 2008, 41, 1618; (g) D. Samanta and P. S. Mukherjee, Chem. Commun., 2014, 50, 1595; (h) N. J. Young and B. P. Hay, Chem. Commun., 2013, 49, 1354; (i) P. Thanasekaran, C.-C. Lee and K.-L. Lu, Acc. Chem. Res., 2012, 45, 1403; $(j)$ B. Therrien, Chem. Eur. J., 2013, 19, 8378; (k) T. R. Cook, V. Vajpayee, M. H. Lee, P. J. Stang and K.-W. Chi, Acc. Chem. Res., 2013, 46, 2464; (l) J. K. Clegga, F. Li and L. F. Lindoy, Coord. Chem. Rev., 2013, 257, 2536; (m) M. L. Saha, S. Neogi and M. Schmittel, Dalton Trans., 2014, 43, 3815.

3 (a) B. H. Northrop, H.-B. Yang and P. J. Stang, Chem. Commun., 2008, 5896 and references therein; (b) M. Fujita, S.-Y. Yu, T. Kusukawa, H. Funaki, K. Ogura and K. Yamaguchi, Angew. Chem., Int. Ed., 1998, 37, 2082; (c) L. Xu, L.-J. Chen and H.-B. Yang, Chem. Commun., 2014, 50, 5156 and references therein; $(d)$ N. Das, A. M. Arif, P. J. Stang, M. Sieger, B. Sarkar, W. Kaim and J. Fiedler, Inorg. Chem., 2005, 44, 57984; (e) N. Das, P. J. Stang, A. M. Arif and C. F. Campana, J. Org. Chem., 2005, 70, 10440.

4 (a) C.-F. Chen, Chem. Commun., 2011, 47, 1674 and references therein; (b) Y. Jiang and C.-F. Chen, Eur. J. Org. Chem., 2011, 6377 and references therein; (c) C.-F. Chen and Y.-X. Ma, Iptycene Chemistry: from Synthesis to Applications, Springer-Verlag, Berlin, 2013; (d) J. H. Chong and M. J. MacLachlan, Chem. Soc. Rev., 2009, 38, 3301 and references therein; (e) A. K. Crane, B. O. Patrick and M. J. MacLachlan, Dalton Trans., 2013, 42, 8026; (f) A. K. Crane, E. Y. L. Wong and M. J. MacLachlan, CrystEngComm, 2013, 15, 9811; $(g)$ M. Mastalerz, Synlett, 2013, 781 and references therein; $(h)$ L. Zhao, Z. Li and T. Wirth, Chem. Lett., 2010, 39, 658; (i) S. Chakraborty, S. Mondal and N. Das, Inorg. Chim. Acta, 2014, 413, 214; $(j)$ Y. Han, Z. Meng, Y.-X. Ma and C.-F. Chen, Acc. Chem. Res., 2014, 47, 2026 and references therein.

5 (a) T. M. Swager, Acc. Chem. Res., 2008, 41, 1181; (b) B. VanVeller, D. Robinson and T. M. Swager, Angew. Chem., Int. Ed., 2012, 51, 1182; (c) B. VanVeller, D. J. Schipper and T. M. Swager, J. Am. Chem. Soc., 2012, 134, 7282; (d) S. Mondal, S. Chakraborty, S. Bhowmick and N. Das, Macromolecules, 2013, 46, 6824; (e) C. Zhang, Y. Liu, B. Li, B. Tan, C.-F. Chen, H.-B. Xu and X.-L. Yang, ACS Macro Lett., 2012, 1, 190; (f) C. Zhang, Z. Wang, J.-J. Wang, L. Tan, J.-M. Liu, B. Tan, X.-L. Yang and H.-B. Xu, Polymer, 2013, 54, 6942; (g) C. Zhang, J.-J. Wang, Y. Liu, H. Ma, 
X.-L. Yang and H.-B. Xu, Chem. - Eur. J., 2013, 19, 5004;

(h) S. Mondal and N. Das, RSC Adv., 2014, 4, 61383.

6 (a) C. Azerraf and D. Gelman, Organometallics, 2009, 28, 6578; (b) C. Azerraf and D. Gelman, Chem. - Eur. J., 2008, 14, 10364; (c) A. Ishii, N. Nakata, R. Uchiumi and K. Murakami, Angew. Chem., Int. Ed., 2008, 47, 2661; (d) A. Ishii, H. Kamon, K. Murakami and N. Nakata, Eur. J. Org. Chem., 2010, 1653; (e) N. Nakata, R. Uchiumi, T. Yoshino, T. Ikeda, H. Kamon and A. Ishii, Organometallics, 2009, 28, 1981; (f) Y. Yamaguchi, N. Nakata and A. Ishii, Eur. J. Inorg. Chem., 2013, 30, 5233; (g) S. Toyota, H. Okuhara and M. Ōki, Organometallics, 1997, 16, 4012; (h) H.-B. Yang, K. Ghosh, N. Das and P. J. Stang, Org. Lett., 2006, 8, 3991.

7 (a) S. Chakraborty, S. Mondal, Q. Li and N. Das, Tetrahedron Lett., 2013, 54, 1681; (b) S. Chakraborty, S. Mondal, S. Bhowmick, J. Ma, H. Tan, S. Neogi and N. Das, Dalton Trans., 2014, 43, 13270; (c) A. Dubey, A. Mishra, J. W. Min, M. H. Lee, H. Kim, P. J. Stang and K.-W. Chi, Inorg. Chim. Acta, 2014, 423, 326.

8 J. Manna, C. J. Kuehl, J. A. Whiteford and P. J. Stang, Organometallics, 1997, 16, 1897.

9 S. Leininger and P. J. Stang, Organometallics, 1998, 17, 3981.

10 (a) S. Leininger, M. Schmitz and P. J. Stang, Org. Lett., 1999, 1, 1921; (b) C. J. Kuehl, C. L. Mayne, A. M. Arif and
P. J. Stang, Org. Lett., 2000, 2, 3727; (c) Y. K. Kryschenko, S. R. Seidel, A. M. Arif and P. J. Stang, J. Am. Chem. Soc., 2003, 125, 5193; (d) H.-B. Yang, A. M. Hawkridge, S. D. Huang, N. Das, S. D. Bunge, D. C. Muddiman and P. J. Stang, J. Am. Chem. Soc., 2007, 129, 2120.

11 Z. Chen and T. M. Swager, Macromolecules, 2008, 41, 6880.

12 (a) H.-B. Yang, K. Ghosh, N. Das and P. J. Stang, Org. Lett., 2006, 8, 3991; (b) M.-C. K. Wong and V. W.-W. Yam, Acc. Chem. Res., 2011, 44, 424; (c) C.-H. Tao and V. W.-W. Yam, J. Photochem. Photobiol., C, 2009, 10, 130; (d) S. Li, J. Huang, F. Zhou, T. R. Cook, X. Yan, Y. Ye, B. Zhu, B. Zheng and P. J. Stang, J. Am. Chem. Soc., 2014, 136, 5908; (e) S. Shanmugaraju, H. Jadhav, Y. P. Patil and P. S. Mukherjee, Inorg. Chem., 2012, 51, 13072; (f) S. Shanmugaraju, A. K. Bar, K.-W. Chi and P. S. Mukherjee, Organometallics, 2010, 29, 2971; (g) J. Zhang, X.-D. Xu, L.-J. Chen, Q. Luo, N.-W. Wu, D.-X. Wang, X.-L. Zha and H.-B. Yang, Organometallics, 2011, 30, 4032; (h) W. Wang and H.-B. Yang, Chem. Commun., 2014, 50, 5171 and references therein; ( $i$ ) D. Samanta and P. S. Mukherjee, Dalton Trans., 2013, 42, 16784.

13 J. J. P. Stewart, J. Mol. Model, 2007, 13, 1173.

14 N. Das, A. Ghosh, A. M. Arif and P. J. Stang, Inorg. Chem., 2005, 44, 7130.

15 T. Yoshida, T. Matsuda, S. Otsuka, G. W. Parshall and W. G. Peet, Inorg. Synth., 1990, 28, 122. 